\title{
Implementing Gender Issues in ICT
}

\author{
N.A. Flipsen \\ Th.P. van der Weide \\ Institute for Computing and Information Sciences \\ Faculty of Science \\ Radboud University Nijmegen \\ The Netherlands
}

\begin{abstract}
The rapid technological changes caused by ICT have a strong impact on global societies. This will lead to changes in the traditional role patterns. In this paper we focus on an academic master course to create gender awareness in ICT development with a special emphasis on developing countries.

First we analyze the impact of ICT on society, and derive requirements from society on the introduction of new ICT applications. We transform these requirements into course objectives, and discuss and motivate our strategy to obtain these objectives in the master course. Then we decompose the course objectives and derive a course program.
\end{abstract}

\section{Introduction}

The rationality of technological progress is to improve the standard of living of a group of people. Yet not all members of that group will in general benefit equally. For women an improvement of their life circumstances is not always so obvious. In many cases, because of traditional role patterns, there frequently are clear obstacles in a society which causes that both sexes do not benefit equally from the advantages of economic progress (McGregor \& Bazi, 2001). See also (Hafkin \& Huyer, 2002)

Worldwide women have a lower social position and fewer opportunities than men to improve their position in a comparable position. Furthermore, women have a more than proportional share in reproductive and household tasks. As a consequence, women in general have less access to power, education and productive sources than men, and thus fewer options than men to cooperate productively in the economy. Traditional social ways of thinking cause many of these barriers (McGregor \& Bazi, 2001).

Sustainability of development work may greatly depend on the flexibility to adapt the existing social

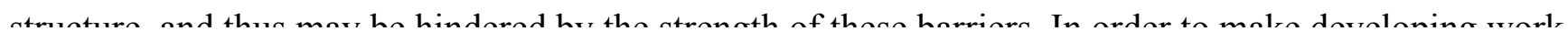


sustainable, reconsideration of the existing societal structures therefore is of great importance.

There also is a clear recognition of these needs and interests at governmental level (see for example Ratgeber \& Adera, 2000). An even representation of women at higher managerial levels of decision making is essential to guarantee the basic access to the new technology (Primo 2003).

In this paper we will frequently use the term 'gender', and will use this term according to the description of (McGregor \& Bazi, 2001):

Whereas the sex of an individual is biologically determined, gender refers to the socially constructed definition of women and men and the relationship between them. Gender is culture-specific and also varies over time. It determines the conception of tasks, functions and roles attributed to women and men in society, in both public and private life.

In (Marker, McNamara, \& Wallace, 2002) we read the advice of the Department for International Development (DFID) not to overestimate technology:

The study concludes that access to ICTs should not be seen as an end in itself; the measure of success remains progress towards reaching the International Development Targets, rather than the spread of technology or bridging the digital divide.

However, addressing the information and communication needs of the poor and creating information rich societies is an essential part of efforts to tackle poverty.

Properly deployed, ICTs have enormous potential as tools to increase information flows and empower poor people.

DFID and other development partners should work closely with developing countries to maximise the contribution of the full range of ICTs to achieving the International Development Targets.

So ICT is recognized as an essential opportunity to tackle poverty. The conclusions of this study are as well applicable in the context of the master course we are aiming at:

The study recommends that, in its approach to ICT issues, DFID should:

- Mainstream attention to the information and communication aspects of poverty and appropriate use of ICTs in the development process

- Address information and communication issues in national poverty reduction strategies;

- Focus on creating the right enabling environment for the spread of ICTs, for entrepreneurship and innovation, and the free flow of information 
- Help the poorest address their information and communication needs;

- Improve and focus the response of the international community;

- Strengthen developing countries' voice in international negotiations on ICT issues.

The intention of this paper is to describe the set-up and motivation of a master course in which the introduction of ICT in relation with gender-sensitive aspects plays a central role. The goal of the course is to train academic students to understand these problems and to be competent to do fundamental research and to make motivated applications at all levels in society.

The structure of this paper is outlined as follows. In this section we have discussed the need for ICT education in developing countries and why gender issues play an essential role. In the next section we further focus on societal effects of ICT from a better understanding of the impact of ICT, and come to a more indepth requirements analysis for this course. In section 3 we present the teaching goals of our master course and argue that the requirements as formulated in the first two sections are a consequence of these goals. In section 4 we decompose these overall course goals into the components of a training program. For each component we describe its sub goals and describe how this is achieved by overviewing the contents. Then in section 5 we describe our experiences so far. In section 6 we close our paper with some conclusions and recommendations.

\section{Gender awareness in ICT education}

At all kinds of levels we see technological changes happening in a rapid pace. In many cases we observe an exponential growth:

1. Computational speed: For many years already computational speed is increasing with exponential growth. If we link this to the transistor density in integrated circuits, this phenomenon is known as Moore's Law (Moore, 1965).

2. Storage capacity: the amount of data to be stored on a surface also shows a similar exponential growth for many years.

3. Connectivity: the number of people that are connected to the Internet also increases exponentially.

4. Information supply: the amount of information being offered exceeds the human processing capacity and is also growing exponentially for some time now. Making information useful requires distillation and filtration.

5. Information devices: many devices in some way handle information and are connected via Internet. An example is the mobile phone. 
and the wireless technology (think for example about the impact of route planners).

The Internet has entered especially the Western world with an enormous speed. A special characteristic of the Internet is that from its very beginning it has been a sharing technology. Sharing technology and information on the Internet have been a guiding principle in the history of the Internet.

As a consequence of all these technical innovations, we also see an explosion of new applications. The first generation Internet applications, nowadays also referred to as Web 1.0, can be characterized as disclosing information for (any) other(s). There is a clear separation between information offer and information use. The central issue is sharing our own information with everybody.

Since a number of years we have the Web 2.0 technology, a change in browser technology making interaction between information supplier and consumer so obvious that the distinction between these two categories is fading. As a consequence, the central issue becomes the common development and maintenance of knowledge sources. A typical example is the online encyclopaedia Wikipedia.

We will link our considerations to the Web 2.0 technology, even if there are already ideas about how the next generation(s) of web technology (Web 3.0, Web n.0) may look like.

An important characteristic of Web 2.0 for our purposes is the availability of enormous amounts of information and the dramatic increase of communication options on the Internet. As a consequence, the phenomenon of working at home all of a sudden becomes a realistic alternative, and large-distance cooperation becomes an effective option.

In Figure 1 we summarize the chain reaction that is invoked by the new technology. A new technology leads to the change of meaning of basic values. The effect is a change of cultural patterns, which then leads to an effect on different role patterns.

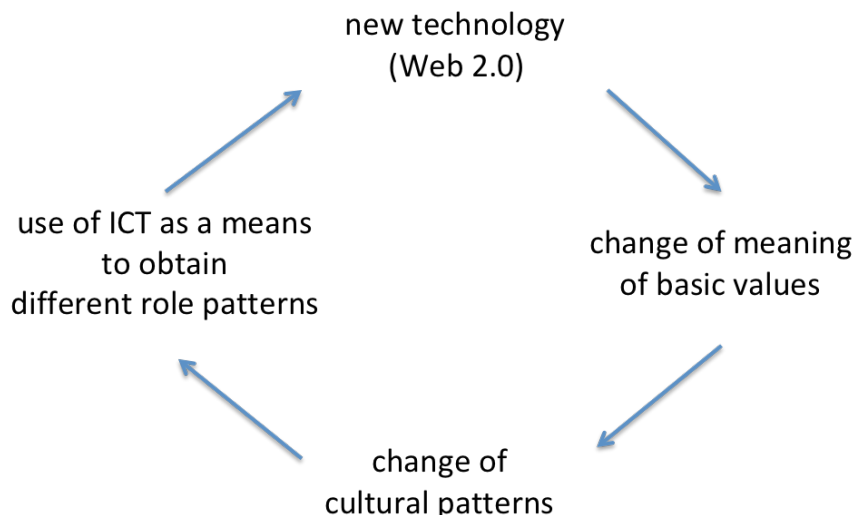


The following list of basic values will need to be reconsidered as a consequence of the new technology and development. On the first place, this list comprises concepts as: copyright, authorship, identity, privacy and trading (Wesch, 2007). For example, as information is freely available for free, the concept of copyright does not seem to be valid anymore.

But this list of changing basic values also is about such concepts as:

- time

- distance

- information

- communication

- searching

- navigating

By the changing intuitions of these concepts, basic values in life will change, and people will think of new strategies to optimize these values in their daily life. This will lead to a substantial change in attitude of people, and thus (in terms of Hofstede, see Shore \& Vekatachalam, 1996) to the "collective programming", the cultural "software of the mind", of their society. It will lead to substantial changes in cultural patterns in society and the organization of our way of sharing life. Typical questions are:

- What do we know, how do we learn?

- How do we deal with that?

- How do we share?

- How do we collaborate?

- How do we balance between the various values?

This obviously also applies to the academic context. First we notice that the impact of ICT is that there is no way research and education could ignore it. The motivation to give ICT research and education a special place is formulated, see (UN General Assembly, 2001), principle 7 and 8.

In the context of education we need to realize there are large groups worldwide who are lagging behind. Not only educational methods need adaption to include special techniques for these disadvantaged groups. We also will have to overcome barriers as mentioned in the previous section, caused by traditional social ways of thinking (McGregor \& Bazi, 2001). An overall approach to protect basic rights of disadvantaged groups is to define a universal charter of rights. See ICT Policv and Internet rights (APC. 2008) for a restriction to see the 
We furthermore focus on the changes related to role patterns in general, and the so-called gender issues in particular. In the research of Nancy Hafkin en Nancy Taggert (Hafkink \& Taggert, 2001) it has been shown that there are perceptible delays in the area of ICT.

Besides this, we have been led by the 'Plan of Action' from the Common Wealth Secretariat in Being (Commonwealth Secretariat, 2005), with as special target the speed up of the 'empowerment' process for women. In this plan is formulated that government and other actors have to introduce an active and visible 'gender mainstreaming' policy in all their policy documents and programs.

We conclude that gender needs special attention in the context of these fast changes. The challenges are on the issue of creating an environment conscious society in which a harmonious and justified cooperation between both sexes is of great importance for a positive economic development, in particular on the area of ICT. We based ourselves on the Women's Rights and the Internet (Yu, 2002).

Summarizing, we may describe the requirements for our master course as follows:

Make academic students aware of gender issues in ICT in such a way that they can find modern ICT solutions for complex problems in the context of a changing environment.

\section{The master course objectives}

\subsection{Objectives of the course}

The objective of this 'Gender Issues in ICT' course is to enhance 'gender awareness' with young academics in the field of ICT, meaning training them to become knowledgeable and sensitive about where and how manwoman related traditional patterns can play a significant role within ICT applications used in the society.

The end-terms for this course are defined as follows:

\section{Students}

- can relate gender issues in ICT to economic values

- will have a common understanding of gender issues in ICT

- aro ahlo to annly oonder awaronoss 
- in practical situations

- at different levels of education

- in the context of city and rural environment

- from a global point of view

- to

- improve that practical situation using ICTs

- set up a research theme in the area of gender \& ICT

To achieve the practical goals this course is organized as a practicum. The participants are divided into smaller groups. Each group has chosen a society relevant subject for further research by the course material provided. After the course these research results are offered to a society oriented representative.

\subsection{The educational approach}

In order to motivate our educational approach, we use the architectural model of competence as proposed in (Roe, 1999). The architecture is displayed in Figure 2 for the context of the master course.

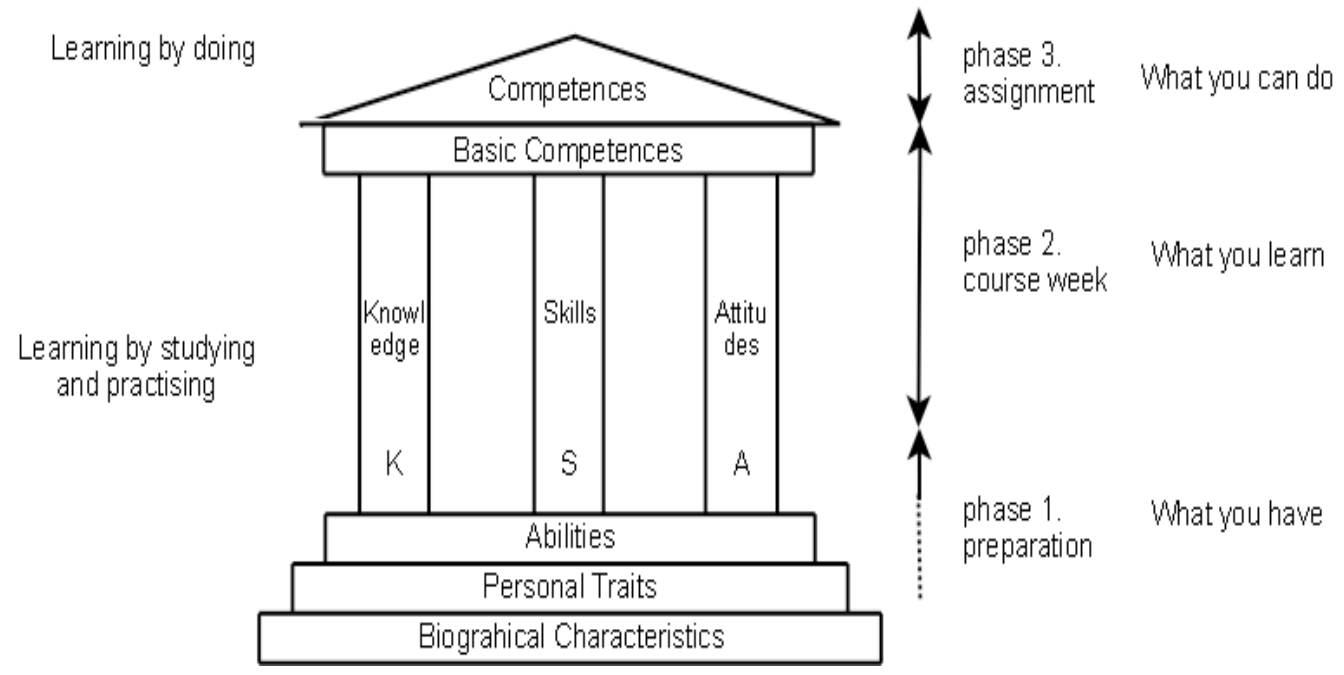

Figure 2. The architectural model of competence

In this architecture we see how personal qualities relate via KSA (knowledge, skills and attitudes) to competences. According to (Roe, 2008) competencies in an organizational setting are defined as follows:

There are several ways to define competences in organisational settings. We prefer to define competences as relating to “an acquired capacity to adequately perform a task, role or mission” or as "sots of hohrvisurs that aro instumontal in tho dolivom, af dosirod rosults ar sutromos" Comnotonsos 
provide a unique integration of knowledge, skills and attitudes that matches requirements following from the task (role or mission) and the setting in which this is to be performed.

In the sections 1 and 2 of our paper we have derived the required competences. These competences are reflected in the end-terms 3 and 4.

To train these competences, the participants will work on a practical project where gender issues are playing an essential role in an ICT application. The other part of the end-terms may be seen as strengthening the KSAs (knowledge, skills and attitudes) and basic competences to the level that is required for these competences.

During the course we train these KSAs, the practical exercises train the basic competences. According to (Roe, 2008)

Competences should therefore be distinguished from knowledge, skills and attitudes, which can be considered independently of the context in which they are applied. Competence is never absolute. It is always relative to some setting or context, and defined in terms of the degree to which someone meets or fails to meet some externally defined standards. For the same reason, competence should also be differentiated from dispositions, i.e. abilities, personality traits and stable characteristics such as interests and values.

\section{The master course implementation}

\subsection{Set-up of the course}

The course (6ec) is divided in 3 phases ( $1 \mathrm{ec}$, European credit, equals 28 working hours; so 6ec corresponds to $168 \mathrm{~h})$.

As this course is intended to be accessible for a broad audience, we have chosen to work with a delayed admission procedure during the preparation phase of the course. The advantage is that interested students can try to enter the course at the risk of a small investment during this first phase.

\subsubsection{The preparation phase $(1 \mathrm{ec})$}

The intention of thic firct nhace ic to hrine the narticinante noccihly from different hackornunde on the entry 
level for the fundamental phase, reaching a common understanding of basic ICT knowledge and of gender issues.

The students will be assigned a case and have to make a description and requirements analysis. For this purpose, the students are organized in smaller teams. Their different backgrounds are used to form multidisciplinary teams.

In terms of the architectural competence model (Figure 2), this phase will bring the participants to the required disposition: their abilities, personality traits and biographical traits.

\subsubsection{The fundamental phase (1 ec)}

During this 1 week there will be internationally oriented lectures in the morning. The afternoon is meant for practical study and further detailing of their research subject using the material offered in the morning sessions.

Every day a closing session is organized to evaluate and give feedback.

Hereafter, the students have made an analysis of the needs of their case described in a project plan, along with an improvement statement, and implementation steps. It will also indicate how and why ICT is being used, and how gender issues are taken care of.

A case example; an administration centre wants to improve their service level.

The participants implement the introduction of an ICT infrastructure that takes benefit from the existing employment structure.

To make the solution sustainable, the three level approach is used, as described in the management hierarchy (the control pyramid). The participants have to explain their contribution at each of these three levels.

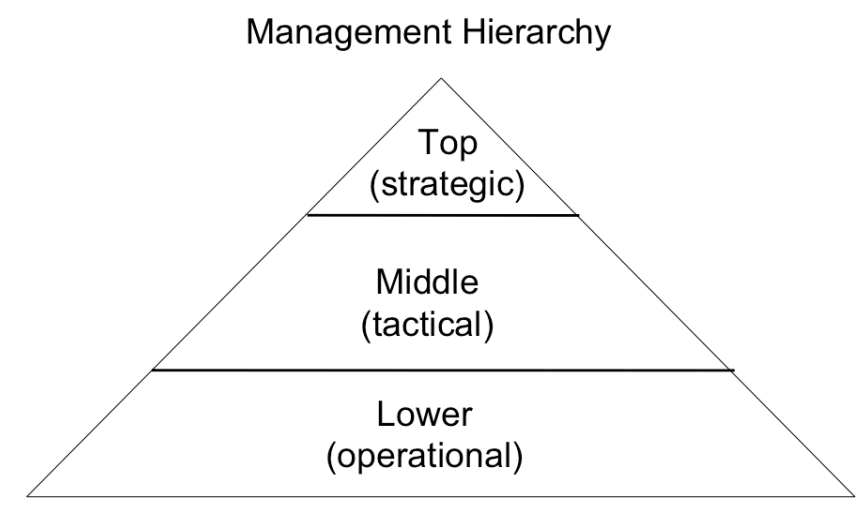


Figure 3. The three levels

The strategic level is for long-term decisions. The tactical level is for mid-term decisions following the plans from the strategic level, conveying the feedback from the operational level. At the operational level we find the short-term decisions, the level where individual entities are handled. In terms of risk management, the cost of a wrong decision at the operational level is relatively low; a cost of a wrong decision at the strategic level is high.

\subsubsection{The practical phase $(4 \mathrm{ec})$}

In this final phase the project plan is carried out, and the participants summarize their findings in their project report.

\subsection{Setting up the fundamental phase}

The fundamental phase is intended to learn the participants the required KSAs, and to train some basic competencies. This phase consist of an intensive 5-day workshop, and is highlighting the following themes of reference:

1. New ICT developments and their impact on society

2. Gender concepts

3. An historical and international approach

4. The situation in Uganda

5. Research

We will discuss these themes in further detail in the following sub sections.

\subsubsection{The new ICT developments and their impact on the society}

The intention of this lecture (and the following) is to give the participants "a common understanding of gender issues in $I C T^{\prime \prime}$.

In this lecture special attention is given to the rapid technological developments and the impact of exponential growth is further defined by some clear examples. In an overview new types of applications are shown, restricting to Web 2.0, XML and agent technology. Arguments are discussed on why we speak of a digital (r)evolution. 
Next to that some societal aspects are highlighted which will fundamentally change by this technological growth. To describe the effect with possible cultural changes, we relate to the cultural model of Hofstede (Shore \& Vekatachalam, 1996). Not only do we point out the possibilities of the new technology, we also address some of the dangers of this new technology and discuss ethical related issues.

We further look at the situation for the EU25 and see that (like with the industrial revolution) there is an effect on the population distribution related to labour and family may be expected (Institute for Family Policies, 2008). The industrial revolution has led to a significant increase of the population, which can be described with the Plateau Model (Verhulst, 1838) for population growth. Using this model, it may show the effect of the Digital Revolution might lead to a decrease of the global population.

The industrial revolution has had an important impact on the nowadays roles in the society. Industrialization resulted in a separation between work and family, which led to a stronger separation between children education and earning activities.

Using the growth model of Nolan (King \& Kraemer, 1984) the transition to the so-called network society (Leevers, 2004) is discussed, and in terms of a simple model (Shenkar \& Luo, 2003) the critical conditions to become and stay a member of the world community are clarified.

The specific position of the changing role patterns in this process of societal change are positioned in these developments. We look at the position of women both in the area of sciences in general as in the area of ICT applications in particular. Here we refer to ICT in a broad sense, going beyond the scientific aspects of ICT. We discuss misconceptions in society and of delays and effects on the learning process.

Finally, we reflected on to what extend these changes have had an impact on the level of policy making. It may be because of new technology the term democracy will have to be reconsidered. As an example we use the trias politicas, which leads to the following description of Human Internet Rights, as pointed out by ICT Policy \& Internet Rights (APC, 2008) using the model of Human Rights. We also zoom in on the gender related effects and further specification of Internet Rights (Yu, 2002).

\subsubsection{Gender concepts}

The second day we focus on gender concepts themselves. As a starting point the concept identity is being illustrated and further refined into (1) tools that you use, (2) things that you do and (3) questions that you ask. 
is put into context, and the recognition is derived as a common factor for both development and sustainability. But that implies the recognition of the importance of quality of life and environment. This brings us to the kernel of the gender issue with key concepts as (1) gender neutral, (2) gender aware (3) gender sensitive, (4) identity, (5) values, (6) roles, (7) equality and (8) equity.

For a good analysis of the gender share in some situations, we need to answer the following questions:

1. who is doing what with which tools?

2. who has access to those tools, the benefits and the opportunities?

3. who controls these tools, the benefits and the opportunities?

These are all related to the various social levels (cultural, political system, legal system, groups, family).

Next we interact on the approach to a balanced treatment and the barriers on the several levels (political, economical, social-cultural and environmental). Information and communication play a crucial role, so there is a clear role for ICT. But for the successful utilization of technology not only the right format is of importance. It also has to be considered how the system will be used and what its political and societal impact will be.

This then brings us to the conclusion:

\section{Gender is an integral aspect of development and ICT}

\subsubsection{A historic and international perspective}

The third day of the course gender issues are highlighted from a historical and international point of view. The intention of this and the following lecture is to give the participants "can relate gender issues in ICT to economic values".

History shows that the introduction of new technology may lead to a new population divide. In the case of ICT this is referred to as digital divide. ICT looks promising as it promises access to the new global market, new investments and e-commerce. But instead it has led to yet another population divide because of the inequality that originates from the restrictions in access to this new technology (Pande, 2006). In particular women are hindered by these restrictions.

As an example the introduction of call centres in India is discussed. It appears that women will get new functions, but still they are the lowest in hierarchy. As a consequence, the labour conditions for women did not improve as a result of the introduction of this new technology (Pande, 2005). 
To better position the issues the international situation of women is discussed in the context of the situation in India. The gender dis balance is clearly visible in the Indian society. The traditional role patterns, norms and values are not advantageous for women. There is no investment in women, they are given to their family in law. The underlying idea is the old ideology stating that there is no need for a woman to learn to be independent, as a child she can rely on her father, as an adult on her husband and when she has grown old she has her sons.

The introduction and implementation of ICT is seen in India as a very important development. It could amongst others work as a strategic driver to make an international connection and to bridge the gap of cultural differences.

But there still, remain a number of large barriers when it comes to ICT employment:

- in general women still work mostly in lower functions;

- access to ICT is burdened by illiteracy, distance, time and language but also social and cultural circumstances;

- few women choose for a scientific education.

\subsubsection{The situation in Uganda}

The fourth day the Ugandan situation is the central subject. We overview the situation in Uganda and focus on opportunities by "relating gender issues in ICT to economic values".

The introduction of ICT applications is of recent date in Uganda. In the presentation (Madanda, 2008) computing and the mobile phone are the main subjects. The usage of the mobile phone in Uganda is farstretching and has a deep impact in society already. At this moment it is not visible yet if ICTs are just tools for new technological developments or industry based developments, or if the impact will be effecting social interaction and will lead to restructuring of this very society.

In comparison with other developing countries and even with developed countries Uganda practices a progressive gender policy. On the various levels 'gender mainstreaming' policies have been written with an active out-role in society.

Research has shown that women with paid jobs are still held responsible for the traditional role patterns of reproductive and household obligations. This explains why there still is a measurable difference in the amount of working hours a day for men and women: a man's average is 8-10 hours, while woman usually vxorl 17.18 hourc on averase Neyt to onvernment alen on arademir level initiativec develon Makerere has 
already put a progressive gender policy at place.

The separate Gender Mainstreaming Division has launched the following program (http://gender.mak.ac.ug/):

The Gender Mainstreaming Programme of Makerere University was approved by Senate and Council in 2001/02 with a mandate to mainstream gender in the University functions of Teaching and Learning, Research, Knowledge Transfer Partnerships and Networking, Governance and Administration, Students and Staff Welfare, Data Management and the Organisational Culture.

One of its key objectives is, to promote and advocate for the enactment and effective implementation of gender responsive policies in Makerere University.

This policy we also find on faculty level. One example is the 'Female Scholarship Initiative', a way to have more women enrol into exact sciences. Another example is the information science program (Cisco Certified Networking) of the Faculty of Social Sciences, an international training program in which gender is streamlined on economic, political, international and social-cultural aspects.

When we look at local level, ICT related gender initiatives are organized from national and local women's organisations. One of their main activities is to advocate and sensitize gender issues'.

One of the women's organisations called 'Women of Uganda Network' (WOUGNET, 2008) is a good example.

By (Adeya, 2001) the following research areas are mentioned for further research:

- the social impacts of ICT

- the influence of attitudes, expectations, organisation and the management of ICT impact

- the relationship between ICT and poverty

- ICT curricula

- the kind of technical problems women encounter

- what exactly is meant by 'women-friendly 'systems

The social relevancy is emphasized by (Adeya, 2001):

75 Sonsitivitu, to rondor iscuos is sfton ionnrod in tho snntort of ICT dovolonmont with manu, whmon 
excluded from access to information. However, where communication technologies have been made available, they can lead to a new era of information democratization. In some cases, African women are now able to discuss issues once considered 'taboo', especially with the anonymity provided by the ICTs.

\subsubsection{PhD Workshop}

At the fifth day a special $\mathrm{PhD}$ workshop Gender Issues in ICT is organized. The intention of the $\mathrm{PhD}$ workshop is to bring researchers and practitioners together to explore the issues and challenges related to all aspects of gender issues in ICT in a society that is changing by ICT. The master course students will also participate in this $\mathrm{PhD}$ workshop.

\section{Experiences}

\subsection{Student evaluation}

The participating students had two different backgrounds. There were students with an ICT background from the Faculty of Computing and Information Technology, and students from the Department of Women and Gender Studies having a non-technical background.

It appeared that the course was accessible for students with rather different backgrounds. All students were positive, and responded that the course offered valuable new knowledge. They felt that the practicum gave them the opportunity to link the newly acquired knowledge to relevant aspects in daily life in Uganda. The students also indicated they would prefer the course to develop and extend a practical part in the coming years to grass root level projects, coming directly from the society (outreach programs), as a consequence most important target groups will be reached.

Two quotes from the students evaluation:

"This is a very good program that would be of great benefit to Ugandans, however to realize for full benefits there's need for actual implementation eg. case study to see how this can actually benefit us [the community] accordingly."

"To note is that the workshop has been very well organized, thanks to the organizer. This is a nice course that helps the students to appreciate gender issues. This has been my first time to attend gender 


\subsection{Teacher evaluation}

The teachers experienced the international approach and cooperation to develop and carry out this course as very stimulating. The teachers think still much research is required in the context of Gender Issues in ICT. It also became clear that advocating gender awareness at all levels is of great importance and that this should have a prominent place in the course. The developed educational material may be adapted to the situation in another country to suit its specific circumstances. The workshop could also be adapted to a special target group.

\section{Conclusions and recommendations}

The main conclusion of the participants, organizers and lecturers is that continuation of this course is of great interest in order to effectively influence the heart of society.

Increasing awareness of humans and society and the eventual positive change this will bring along requires ongoing development, training and needs to be repeated on an international level both on a horizontal and vertical level.

As recommendations for this course the following points arose;

- invite more relevant stakeholders on different levels, for instance government level, community level and policy making level

- develop the 'community outreach' aspect as a practical part of the initial concept to also reach out to grass-root level.

- give a clear explanation on the meaning of 'Gender' placed in the beginning of the course.

- identify the relation between gender and development issues in ICT

\section{Bibliography}

- Adeya, C. N. (2001). Information and Communication Technologies in Africa: A Review and Selective Annotated Bibliography 1990-2000. International Network for the Availability of Scientific Publications (INASP), Oxford.

- APC. (2008). APC Internet Rights Charter for social justice and sustainable development. (Association for Progressive Communication). Version at 0913 2008, from APC.org: http://rights.apc.org/charter.shtml 
In W. J. Nijhof, \& L. F. Nieuwenhuis, The learning potential of the workplace (pp. 71-96).

Rotterdam: Sense Publishers.

- Commonwealth Secretariat. (2005). Plan of Action for Gender Equality 2005-2015.

- Derbyshire, H. (2003). Gender issues in the use of computers in education in Africa. Version at 0913 , 2008 from Imfundo (DFIF): http://imfundo.digitalbrain.com/imfundo/web/learn/genderissues/

- GAB. (2008). (U. C. Develo, Producent). Version at 09 13, 2008 from Gender Advisory Board: http://gab.wigsat.org/

- Gastaldo, I., Almerich, G., Diaz, I., Bo, R., \& Suárez, J. (2005). Analysis of ICT training needs according to gender in Primary and Secondary school teachers. Proceedings of the 3rd International Conference on Multimedia and Information \& Communication Technologies in Education (m-ICTE 2005) (pp. 321-325). Badajoz: A.M. Villas et al. (Eds).

- Gillard, H., Mitev, N., \& Scott, S. (2007). ICT Inclusion and Gender: Tensions in Narratives of Network Engineer Training. The Information Society , 23 (1), 19-37.

- Hafkin, N., \& Huyer, S. (2002). Lessons on Gender in ICT Applications: Case Studies of infoDev Projects. infoDev's Working Papers Series .

- Hafkink, N., \& Taggert, N. (2001). Gender, Information Technology, and Developing Countries: an Analytic Study. Washington, DC: WID Office USAID.

- Institute for Family Policies. (2008). Report on the Evolution of the Family in Europe 2008.

- Johnstone, B. (2008, 05 22). Empowering rural women through ICT4D and Small-Scale Agriculture in the Rwenzori Region, Western Uganda. Version at 09 13, 2008 from Kabissa: http://www.kabissa.org

- King, J. L., \& Kraemer, K. L. (1984). Evolution and organizational information systems: an assessment of Nolan's stage model. Communications of the ACM , 27 (5), 465-475.

- Korten, D. C. (1992). People-Centered Development, Alternatives for a World in Crisis. In K. Bauzon (Red.), Development and democratization in the Third World : myths, hopes, and realities (pp. 5377). Crane Russak, Washington.

- Labelle, R. (2005). ICT policy formulation and e-strategy development, a comprehensive guidebook. Elsevier.

- Leevers, D. (2004). From Atoms to bits: From Atoms To Bits Culture, Collaboration and Global Sustainability. International Psychohistorical Association, 27th Annual Convention. New York.

- Markauskaite, L. (2006). Gender issues in preservice teachers' training: ICT literacy and online learning. Australasian Journal of Educational Technology , 22 (1), 1-20.

- Marker, P., McNamara, K., \& Wallace, L. (2002). The significance of information and communication technologies for reducing poverty. Think! Programme. DFIF.

- McGregor, E., \& Bazi, F. (2001). Gender mainstreaming in science and technology. Commonwealth 
Secretariat.

- Moore, G. E. (1965). Cramming more components into integrated circuits. Electronics, 38 (8).

- Pande, R. (2006). Digital divide, gender and the Indian experience in IT. In E. Trauth (Red.), CS majors as well as the NCD majors in the sample. One rule Encyclopedia of Gender and Information Technology, (pp. 191-199).

- Pande, R. (2005). Looking at Information technology from a Gender Perspective: The Call Centers in INdia. Asian Center for Women's Studies , 11 (1), 58-82.

- Primo, N. (2003). Gender Issues in the Information Society. UNESCO Publications or the World Summit on the Information Society.

- Rathgeber, E.-M., \& Adera, E. O. (2000). Gender and the Information Revolution in Africa. International Development Research Centre. Canada: IDCR.

- Shenkar, O., \& Luo, Y. (2003). International Business. John Wiley \& Sons Inc.

- Shore, B., \& Vekatachalam, A. R. (1996). Role of national culture in the transfer of information technology. Journal of Strategic Information Systems , 4, 19-35.

- Sylla, F. S. (2002). ICT as an Instrument for Participation: The Regional Perspective from Africa, Examples of the Internet use at the Grassroots Level. In E. G. United Nations Division for the Advancement of Women (DAW), Information and communication technologies and their impact on and use as an instrument for the advancement and empowerment of women (pp. 11-14). Seoul, Republic of Korea.

- UN General Assembly. (2001). WSIS Outcome Documents 2006. World Summit on the Information Society.

- Verhulst, P. F., (1838). 'Notice sur la loi que la population poursuit dans son accroissement'. Correspondance mathématique et physique 10:113-121.

- Wesch, M. (2007, Jan 31). The Machine is Us/ing Us. Version at 09 13, 2008 from http://mediatedcultures.net/mediatedculture.htm

- Worldbank. (2008). Gender, ICT and Education: What Development Practitioners Need to Know about Gender, ICT and Education.

- WOUGNET. (2008). Women of Uganda Network. Version at 09 13, 2008 from http://www.wougnet.org/

- Yu, C. (2002). ICTs and Gender Equality - Women's Rights and the Internet. Workshop on "The World Summit on The Information Society: The Asian Response", (pp. 22-24). Bangkok. 